\title{
ANALISIS SPASIAL TB PARU BTA POSITIF DI WILAYAH KERJA PUSKESMAS WUNA TAHUN 2015 - 2017
}

\section{SPATIAL ANALYSIS TUBERCULOSIS WITH POSSITIVE SPUTUM IN WORKING AREA OF WUNA HEALTH CENTER AT 2015 - 2017}

\author{
Jumakil $^{1 *}$, Lymbran Tina², Eke Mahendra ${ }^{3}$ \\ *1Fakultas Kesehatan Masyarakat Universitas Halu Oleo, Kampus Bumi Tridharma Anduonohu Jalan H.E.A. \\ Mokodompit, email: makildjoe@gmail.com, Indonesia \\ 2 Fakultas Kesehatan Masyarakat Universitas Halu Oleo, Kampus Bumi Tridharma Anduonohu Jalan H.E.A. \\ Mokodompit, email: Iymbranizzah@gmail.com, Indonesia \\ ${ }^{3}$ Fakultas Kesehatan Masyarakat Universitas Halu Oleo, Kampus Bumi Tridharma Anduonohu Jalan H.E.A. \\ Mokodompit, email: ekemahendra12@gmail.com, Indonesia
}

\begin{abstract}
Background: One area with high rates of positive sputum in West Muna district, high TB patients is in the Wuna Community Health Center work area. Positive smear pulmonary TB sufferers in 2015 recorded 25 positive cases, in 2016 as many as 41 positive cases, whereas in 2017 there was an increase from the previous year which was 45 positive cases.

Objective: To find out the distribution of cases tuberculosis with positive sputum from 2015 to 2017 , then to be related to population density.

Methods: This type of research is observational with spatio temporal modeling, based on geographic information systems.

Results: There has been a shift in the pattern of positive pulmonary tuberculosis pulmonary TB sufferers from 2015 to 2017. TB cases in Maperaha, Nihi, Bungkolo villages have been concentrated in the same area for three years, as well as Waulai Village during 2016 and 2017, in 2015 and 2016 cases of tuberculosis were still concentrated around the same area. Differed in 2017, the concentration of cases shifted to the west.

Conclusion: Cases of tuberculosis with positive sputum in the working area of Wuna Health Center from 2015-2017 have increased, and many occur in villages with fairly population density.
\end{abstract}

Keywords: Population Density, Possitive Sputum, Spatial Analysis, Tuberculosis.

\section{PENDAHULUAN}

Secara global pada tahun 2017, kasus baru tuberkuloisis mecapai 6,3 juta, atau setara dengan $61 \%$ dari insiden tuberculosis (10,4 juta). Tuberculosis sampai sekarang masih tetap menjadi 10 penyebab kematian tertinggi di dunia dan kematian tuberculosis diperkirakan mencapai 1,3 juta. ${ }^{1}$

Indonesia termasuk salah satu negara yang memiliki beban penyakit tuberculosis terbesar dibandingkan negara India, China, Philipina dan Pakistan. Ada beberapa tantangan yang menjadi perhatian yaitu semakin meningkatnya kasus TuberkulosisMDR, Tuberkulosis-HIV, Tuberkulosis dengan Diabetes Militus, Tuberkulosis pada anak. Masyarakat yang tergolong rentan lainnya Tahun 2017 ditemukan kasus tuberculosis sebanyak 425.089 kasus. $^{2}$

Pada tahun 2017 di Sulawesi Tenggara ditemukan 2.587 kasus baru BTA positif, terjadi penurunan jika dibandingkan dengan tahun 2016 dengan 3.105 kasus. Tidak seperti trend yang terjadi pada tahuntahun sebelumnya, Berdasarkan jenis kelamin, seperti tahun sebelumnya, rata-rata 
kasus baru BTA positif pada laki-laki lebih banyak dinadingkan dengan perempuan dengan 59\% berbanding $41 \%$. Proporsi tersebut terjadi di hampir semua kabupaten. ${ }^{3}$

Jumlah kasus baru BTA positif tertinggi rata-rata terjadi di kabupaten/kota yang berpenduduk besar, ini menunjukan bahwa kejadian kasus baru Basil Tahan Asam (BTA) Positif di Provinsi Sulawesi Tenggara tidak merujuk pada karakteristik wilayah tertentu, tapi lebih kepada besar kecilnya jumlah penduduk, ini berarti pula bahwa proporsi kasus BTA Positif di masyarakat relatif merata di semua kabupaten/kota salah satunya Kabupaten Muna Barat. ${ }^{3}$

Jumlah kasus penemuan TB paru BTA positif di Kabupaten Muna Barat menunjukkan pada tahun 2015 ditemukan 72 penderita BTA positif dari 83.364 penduduk dengan prevalensi sebesar 87 per 100.000 penduduk dan pada tahun 2016 ditemukan 40 penderita BTA positif dari 83.364 penduduk dengan prevalensi sebesar 48 per 100.000 pendudukdan pada tahun 2017 ditemukan 116 penderita BTA positif dari 83.364 penduduk dengan prevalensi sebesar 140 per 100.000 penduduk. $^{4}$

Salah satu daerah dengan jumlah penderita TB BTA+ tinggi adalah di wilayah kerja Puskesmas Wuna. Penderita TB paru BTA positif pada tahun 2015 tercatat sebanyak 25 kasus yang positif, tahun 2016 sebanyak 41 kasus positif, sedangkan tahun
2017 mengalami peningkatan dari tahun sebelumnya yaitu sebanyak 45 kasus positif. ${ }^{5}$

Teknologi Geografi Information System (GIS) bermanfaat bagi sistem pengawasan Tuberkulosis. Jarak dapat menjadi pertimbangan dalam metode perencanaan untuk meningkatkan akses bagi mereka yang tinggal jauh dari layanan diagnostik Tuberkulosis, dengan demikian dapat meningkatkan deteksi Tuberkulosis. ${ }^{6}$

\section{BAHAN DAN CARA PENELITIAN}

Jenis penelitian ini adalah observasional dengan pemodelan spatio temporal, berbasis system informasi geografi, yang bertujuan untuk mengetahui persebaran kasus TB BTA Positif setiap tahun dari tahun 2015 sampai dengan tahun 2017, selanjutnya dihubungkan dengan kepadatan penduduk.

Bahan yang digunakan dalam penelitian ini adalah peta shp yang diperoleh dari Badan Pusat Statistik Provinsi Sulawesi Tenggara, serta titik koordinat penderita TB Paru BTA Positif yang berada dalam wilayah kerja Puskesmas Wuna Kabupaten Muna Barat Provinsi Sulawesi Tenggara.

Sampel dalam penelitian ini adalah semua penderita TB Paru BTA Positif yang berobat dan tercatat di Puskesmas Wuna serta dinyatakan positif dari hasil pemeriksaan dahak di laboratorium yang berjumlah 111 orang. Pengumpulan data dilapangan menggunakan kuesioner, dan Global Positioning System (GPS), hasil pengumpulan data diolah menggunakan 
aplikasi microsoft excel, selanjutnya diolah menggunakan aplikasi Sistem Informasi Geografi.

\section{HASIL DAN PEMBAHASAN}

Karakteristik Responden

1. Distribusi Kasus TB Paru BTA Positif berdasarkan Umur.

Tabel 1. Distribusi Kasus TB Paru BTA Positif Berdasarkan Umur Di Wilayah Kerja Puskesmas Wuna selama Tahun 2015-2017.

\begin{tabular}{ccrr}
\hline No. & $\begin{array}{c}\text { Kelompok } \\
\text { Umur }\end{array}$ & Jumlah & \multicolumn{1}{c}{$\%$} \\
\hline 1. & $15-24$ & 12 & 10,81 \\
2. & $25-34$ & 24 & 21,62 \\
3. & $35-44$ & 19 & 17,12 \\
4. & $45-54$ & 30 & 27,03 \\
5. & $55-64$ & 22 & 19,82 \\
6. & $\geq 65$ & 4 & 3,60 \\
\hline & Total & $\mathbf{1 1 1}$ & $\mathbf{1 0 0}$ \\
\hline
\end{tabular}

Sumber: Puskesmas Wuna 2018.

Tabel 1 menunjukkan bahwa penderita lebih banyak pada kelompok umur 45-54 tahun yaitu sebanyak 30 orang $(27,03 \%)$, sedangkan penderita paling sedikit terjadi pada kelompok umur $\geq 65$ tahun yaitu sebanyak 4 orang $(3,60 \%)$.

2. Distribusi Kasus TB Paru BTA Positif berdasarkan Desa.

Jumlah kasus TB Paru BTA Positif di wilayah kerja Puskesmas Wuna dari tahun 2015 sampai dengan tahun 2017 terus mengalami peningkatan. Desa dengan jumlah penderita tertinggi berada pada wilayah Wuna dengan jumlah kasus sebanyak 40 orang $(36,04 \%)$, sedangkan yang terendah pada wilayah Waulai dengan jumlah kasus sebanyak 13 orang $(11,71 \%)$ seperti pada table 2 berikut

Tabel 2. Distribusi Kasus TB Paru BTA Positif Berdasarkan Desa di Wilayah Kerja Puskesmas Wuna Tahun 2015-2017

\begin{tabular}{|c|c|c|c|c|c|}
\hline \multirow{2}{*}{ No. } & \multirow{2}{*}{ Desa } & \multicolumn{3}{|c|}{ Tahun } & \multirow{2}{*}{ Jumlah } \\
\hline & & 2015 & 2016 & 2017 & \\
\hline 1. & Maperaha & 3 & 5 & 2 & 10 \\
\hline 2. & Nihi & 4 & 10 & 8 & 22 \\
\hline 3. & Lafinde & 2 & 5 & 8 & 15 \\
\hline 4. & Wuna & 12 & 13 & 15 & 40 \\
\hline 5. & Bungkolo & 4 & 2 & 5 & 11 \\
\hline 6 & Waulai & 0 & 6 & 7 & 13 \\
\hline & Total & 25 & 41 & 45 & 111 \\
\hline
\end{tabular}

Sumber: Data Primer 2018.

.Jumlah kasus terbanyak yang terjadi di Desa Wuna diakibatkan oleh tingginya angka kepadatan penduduk. Konsentrasi penduduk di wilayah kerja Puskesmas Wuna berada di Desa Wuna.

Berdasarkan tahun kejadian, dari tahun 2015 sampai dengan tahun 2017 kasus penderita TB Paru BTA Positif di Desa Wuna dan Waulai mengalami peningkatan. Desa Wuna merupakan daerah yang sangat berisiko terjadi penularan kasus TB Paru BTA Positif karena merupakan daerah dengan kepadatan penduduk tinggi.

Hal menarik terjadi di Desa Waulai, Tahun 2015 tidak terjadi kasus TB Paru BTA Positif, namun pada tahun 2016 terjadi meningkatan yang cukup besar menjadi 6 kasus, dan kembali meningkat pada tahun 2017 menjadi 7 kasus.

Analisis Spasial

1. Persebaran Kasus TB Paru BTA Positif 
Selama tiga tahun (2015-2017) kasus TB paru BTA positif tersebar di seluruh wilayah kerja Puskesmas Wuna, dengan sebaran kasus terbanyak berada pada Desa Wuna, sedangkan sebaran kasus terendah pada Desa Waulai.

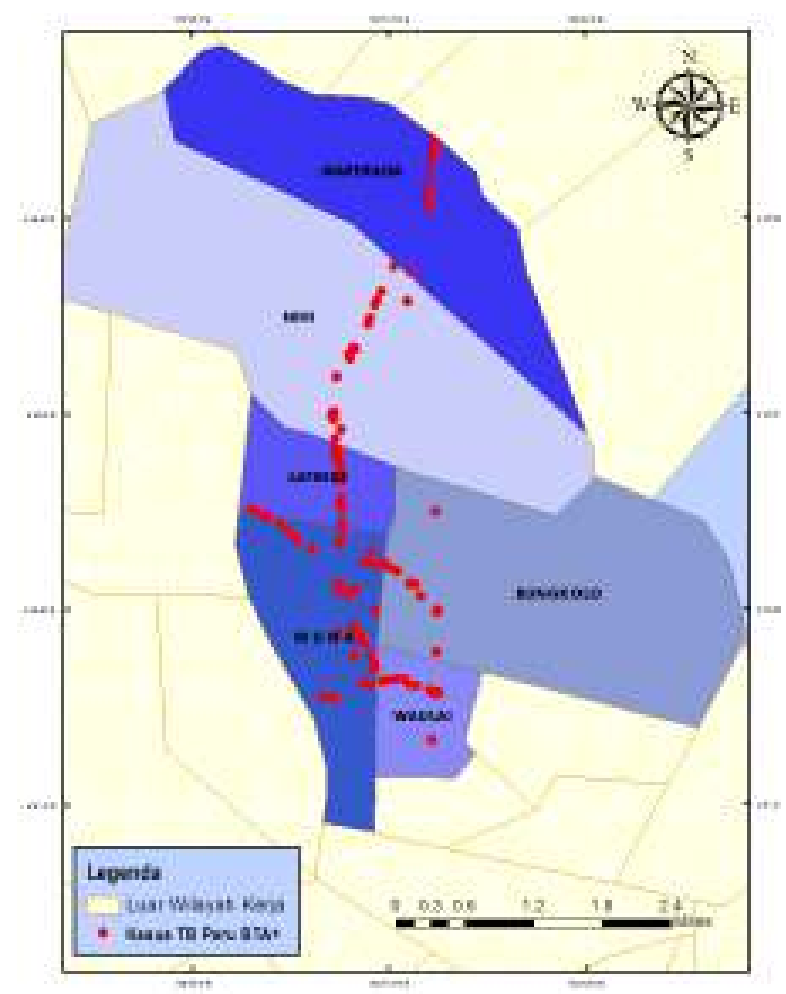

Sumber: Hasil Pengukuran di Lapangan

Gambar 1. Peta Persebaran Kasus TB Paru BTA Positif di Wilayah Kerja Puskesmas Wuna

Tahun 2015-2017

2. Persebaran Kasus TB Paru BTA Positif berdasarkan Tahun.

Perubahan pola pergeseran penderita TB Paru BTA Positif dari tahun 2015 sampai dengan tahun 2017. Kasus TB di Desa Maperaha, Nihi, Bungkolo selama tiga tahun terkonsentrasi pada wilayah yang sama, begitu pula dengan Desa Waulai selama tahun 2016 dan 2017.
Hal yang berbeda terjadi di Desa Wuna. Tahun 2015 dan 2016 kasus TB Paru BTA Positif masih terkonsentrasi di sekitar wilayah yang sama, namun berbeda pada Tahun 2017, konsentasi kasus bergeser ke arah barat, dimana pada tahun 2015 dan 2016 di wilayah tersebut belum pernah ditemukan kasus TB BTA Positif. Hal ini disebabkan karena ada warga di wilayah tersebut yang mempunyai keluarga menderita TB Paru BTA Positif di wilayah yang terdapat penderita pada tahun 2015 dan 2016 tertular dan menularkan kepada warga yang lain di wilayah tempat tinggalnya.

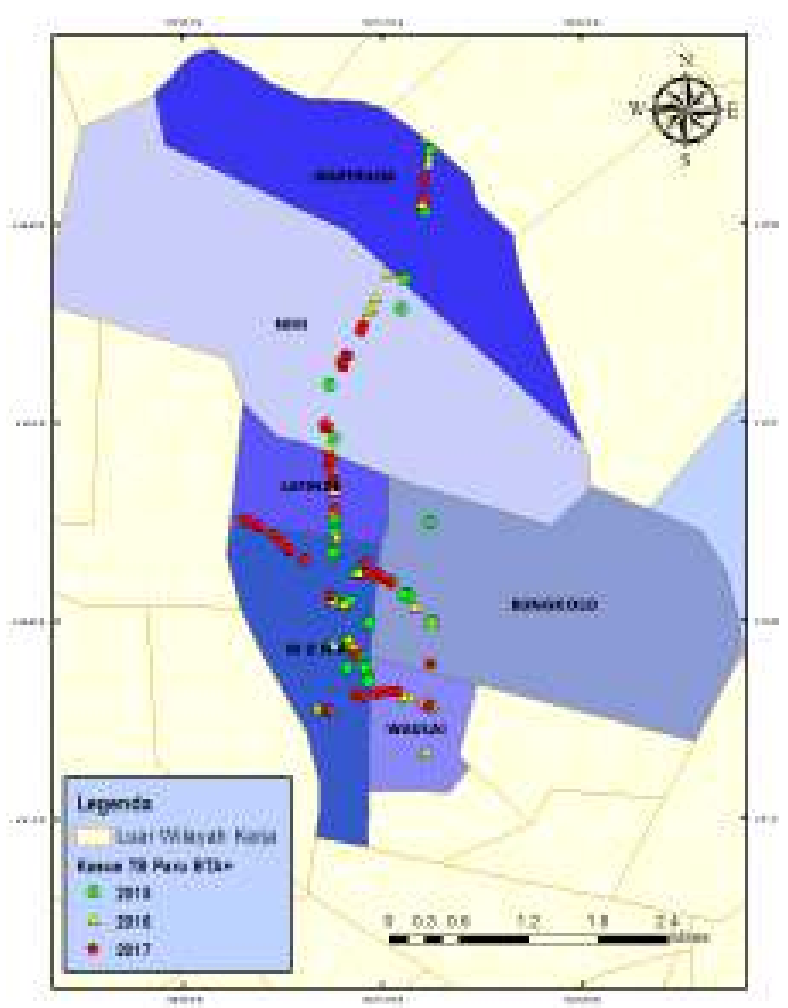

Sumber: Hasil Pengukuran di Lapangan

Gambar 2. Peta Persebaran Kasus TB Paru BTA

Positif di Wilayah Kerja Puskesmas Wuna Berdasarkan Tahun Kejadian

Penderita Tuberkulosis yang masih dalam masa inkubasi memiliki rentang waktu 
sampai didiagnosa, dalam rentang waktu ini dapat terjadi penularan terhadap orang lain. Penularan akan terjadi apabila kekebalan tubuh mengalami penurunan. Kekebalan dari setiap manusia berbeda-beda, dapat dipengaruhi oleh keadaan geografi dan iklim. ${ }^{7}$

Populasi minoritas yang menderita TB Paru BTA Positif dapat menjadi faktor predictor penularan terhadap masayarakat disekitarnya. ${ }^{8}$ Penanganan kasus TB Paru BTA Positif, seharusnya diawali dari rumah tangga penderita yang sangat memungkinkan terjadi penularan apabila terjadi kontak. kasus baru berkaitan dengan penularan sebagian besar mencerminkan penularan dalam rumah tangga. Pencegahan penanganan yang paling baik adalah dengan penanganan rutin dan dilakukan investigasi kontak. $^{9}$

3. Persebaran Kasus TB Paru BTA Positif berdasarkan Kepadatan Penduduk.

Desa dengan tingkat kepadatan cukup padat sangat berisiko terjadi penularan kasus TB Paru BTA Positif. Di desa tersebut terus terjadi peningkatan kasus selama tiga tahun (2015-2017) Di desa yang tingkat kepadatan penduduknya kurang padat juga berisiko namun tidak terlalu besar jika dibandingkan dengan desa yang tingkat kepadatan penduduknya cukup padat. Di daerah dengan tingkat kepadatan kurang padat juga terjadi kasus TB Paru BTA Positif namun tidak terlalu besar dibandingkan dengan desa dengan kepadatan penduduk kurang padat.

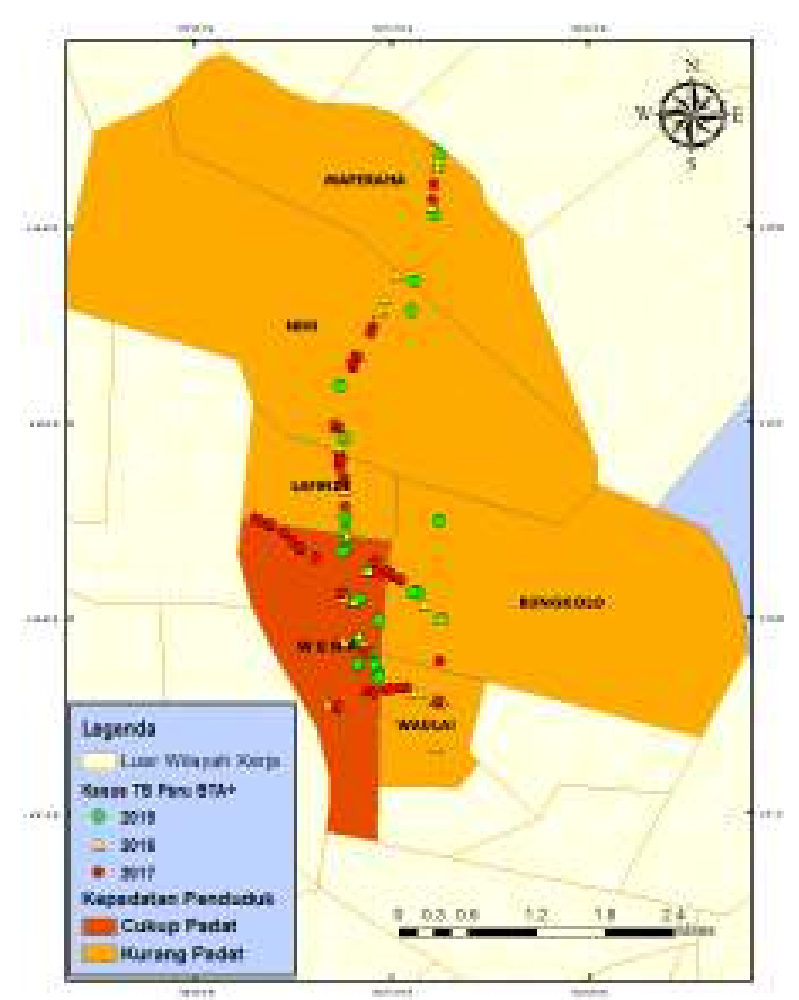

Sumber: BPS Kab. Muna Barat dan Hasil Pengukuran di Lapangan

Gambar 3. Peta Persebaran Kasus TB Paru BTA Positif Berdasarkan KepadatanPenduduk di Wilayah Kerja Puskesmas Wuna

Kejadian TB Paru BTA Positif salah satunya dipengaruhi oleh tingkat Kepadatan Penduduk. Kepadatan penduduk dapat menjadi media penularan tuberkulosis. Keramaian akan lebih memudahkan terjadinya perpindahan penyakit tuberculosis dari penderita ke orang lain. Oleh karena itu daerah dengan tingkat kepadatan yang tinggi menjadi prioritas dalam program penanggulangan dan pencegahan penyakit tuberculosis. ${ }^{10}$

Migrasi manusia dari suatu daerah ke daerah lain, dari negara ke negara lain akan 
menambah angka kepadatan penduduk. Mycobacterium tuberculosis menunjukkan distribusi filogeni terstruktur terkait di seluruh dunia dengan adanya migrasi manusia. Interaksi antar populasi yang berbeda membentuk struktur populasi global mycobacterium tuberculosis pada skala regional. ${ }^{11}$

\section{KESIMPULAN}

1. Peningkatan kasus TB Paru BTA Positif di wilayah kerja Puskesmas Wuna dari tahun 2015-2017

2. Kasus TB Paru BTA Positif terbanyak dan meningkat setiap tahunnya (20152017) terjadi di Desa Wuna.

3. Kasus TB Paru BTA Positif, banyak terjadi di desa dengan tingkat kepadatan cukup padat.

\section{TERIMA KASIH}

1. Yusuf Sabilu, Dr., M.Si, Dekan FKM UHO Kampus Hijau Bimi Tridharma Anduonohu, Jalan H.E.A. Mokodompit Kendari, email: yusufsabilu@yahoo.com

2. La Aba, Dr. M.Si, Ketua LPPM UHO Kampus Hijau Bimi Tridharma Anduonohu, Jalan H.E.A. Mokodompit Kendari,, email: laabaz@yahoo.com

\section{KEPUSTAKAAN}

1. WHO. Global Tuberculosis Report 2017. Genewa: World Health Organization; 2017.

2. Kemenkes. Profil Kesehatan Indonesia 2017. In: R.I. KK, editor. Jakarta: Pusat Data dan Informasi Kementerian Kesehatan R.I.; 2018.
3. Dikes Prov. Sultra. Profil Kesehatan Sulawesi Tenggara Tahun 2017. Kendari: Dinas Kesehatan Provinsi Sulawesi Tenggara; 2018.

4. Dinkes Muna Barat. Profil Kesehatan Kabupaten Muna Barat Tahun 2017. Labungkari: Dinas Kesehatan Kabupaten Muna Barat; 2018.

5. Puskesmas Wuna. Profil Puskesmas Wuna Tahun 2017. Wuna: Puskesmas WUna; 2018.

6. Bui LV, Mor Z, Chemtob D, Ha ST, Levine H. Use of Geographically Weighted Poisson Regression to examine the effect of distance on Tuberculosis incidence: $A$ case study in Nam Dinh, Vietnam. PLoS One. 2018;13(11):e0207068.

7. Zhang $Y$, Wang $X L$, Feng $T$, Fang $C Z$. Analysis of spatial-temporal distribution and influencing factors of pulmonary tuberculosis in China, during 2008-2015. Epidemiology and infection. 2018:1-9.

8. Wubuli A, Xue F, Jiang D, Yao X, Upur $H$, Wushouer Q. Socio-Demographic Predictors and Distribution of Pulmonary Tuberculosis (TB) in Xinjiang, China: $A$ Spatial Analysis. PLoS One. 2015;10(12):e0144010.

9. Yuen CM, Kammerer JS, Marks K, Navin TR, France AM. Recent Transmission of Tuberculosis - United States, 2011-2014. PLoS One. 2016;11(4):e0153728.

10. Pelissari DM, Diaz-Quijano FA. Household crowding as a potential mediator of socioeconomic determinants of tuberculosis incidence in Brazil. PLoS One. 2017;12(4):e0176116.

11. Barbier $M$, Dumitrescu $O$, Pichat $C$, Carret G, Ronnaux-Baron A-S, Blasquez $G$, et al. Changing patterns of human migrations shaped the global population structure of Mycobacterium tuberculosis in France. Scientific reports. 2018;8(1). 